\title{
Anticoagulant treatment satisfaction with warfarin and direct oral anticoagulants for venous thromboembolism
}

\author{
Margaret C. Fang ${ }^{1}$ (D) Alan S. Go $0^{2,3,4,5} \cdot$ Priya A. Prasad ${ }^{1}$. Jin-Wen Hsu ${ }^{6}$. Dongjie Fan ${ }^{2} \cdot$ Cecilia Portugal $^{6}$. \\ Sue Hee Sung ${ }^{2} \cdot$ Kristi Reynolds $^{3,6}$
}

Accepted: 22 March 2021 / Published online: 8 April 2021

(c) The Author(s) 2021

\begin{abstract}
Treatment options for patients with venous thromboembolism (VTE) include warfarin and direct oral anticoagulants (DOACs). Although DOACs are easier to administer than warfarin and do not require routine laboratory monitoring, few studies have directly assessed whether patients are more satisfied with DOACs. We surveyed adults from two large integrated health systems taking DOACs or warfarin for incident VTE occurring between January 1, 2015 and June 30, 2018. Treatment satisfaction was assessed using the validated Anti-Clot Treatment Scale (ACTS), divided into the ACTS Burdens and ACTS Benefits scores; higher scores indicate greater satisfaction. Mean treatment satisfaction was compared using multivariable linear regression, adjusting for patient demographic and clinical characteristics. The effect size of the difference in means was calculated using a Cohen's $d(0.20$ is considered a small effect and $\geq 0.80$ is considered large). We surveyed 2217 patients, 969 taking DOACs and 1248 taking warfarin at the time of survey. Thirty-one point five percent of the cohort was aged $\geq 75$ years and $43.1 \%$ were women. DOAC users were on average more satisfied with anticoagulant treatment, with higher adjusted mean ACTS Burdens (50.18 v. 48.01, p < 0.0001) and ACTS Benefits scores $(10.21$ v. 9.84, p=0.046) for DOACs vs. warfarin, respectively. The magnitude of the difference was small (Cohen's $d$ of 0.29 for ACTS Burdens and 0.12 for ACTS Benefits). Patients taking DOACs for venous thromboembolism were on average more satisfied with anticoagulant treatment than were warfarin users, although the magnitude of the difference was small.
\end{abstract}

Keywords Anticoagulants · Venous thromboembolism $\cdot$ Treatment satisfaction $\cdot$ Direct oral anticoagulants · Warfarin

Margaret C. Fang

margaret.fang@ucsf.edu

Alan S. Go

Alan.S.Go@kp.org

Priya A. Prasad

Priya.Prasad@ucsf.edu

Jin-Wen Hsu

Jin-Wen.Y.Hsu@kp.org

Dongjie Fan

dongjie.j.fan@kp.org

Cecilia Portugal

Cecilia.X.Portugal@kp.org

Sue Hee Sung

Sue.Hee.Sung@kp.org

Kristi Reynolds

Kristi.Reynolds@kp.org
1 Division of Hospital Medicine, University of California, San Francisco, 521 Parnassus Ave., Box 0131, San Francisco, CA 94143, USA

2 Division of Research, Kaiser Permanente Northern California, Oakland, CA, USA

3 Department of Health Systems Science, Kaiser Permanente Bernard J. Tyson School of Medicine, Pasadena, CA, USA

4 Department of Medicine and Department of Epidemiology and Biostatistics, University of California, San Francisco, San Francisco, CA, USA

5 Departments of Medicine, Health Research and Policy, Stanford University, Palo Alto, CA, USA

6 Department of Research and Evaluation, Kaiser Permanente Southern California, Pasadena, CA, USA 


\section{Highlights}

- Few studies have compared whether patients with venous thromboembolism are more satisfied on direct oral anticoagulants (DOACs) or warfarin

- We surveyed 2217 adults taking oral anticoagulants for venous thromboembolism and assessed anticoagulant treatment satisfaction using a validated scale (the AntiClot Treatment Scale)

- Average treatment satisfaction on DOACs was higher than on warfarin, although the magnitude of the difference was small

- Whether treatment satisfaction leads to differential medication adherence or patient behavior is not known.

\section{Background}

Venous thromboembolism (VTE) affects an estimated 500,000 individuals each year in the United States [1]. The mainstay of primary treatment for VTE is therapeuticallydosed anticoagulation, generally for a period of 3-6 months, followed by consideration of further anticoagulation depending on the clinical context [2, 3]. However, anticoagulants can lead to both life-threatening and non-life threatening bleeding, as well as cause patients to alter their lifestyle and behaviors; these could negatively impact quality of life. Oral anticoagulant options for VTE include vitamin K antagonists, most commonly warfarin sodium, and more recently, several direct oral anticoagulants (DOACs) including dabigatran, rivaroxaban, apixaban, and edoxaban. DOACs have advantages over warfarin in terms of ease of use: they have fixed dosing, do not require frequent blood tests for monitoring, and are associated with fewer drug-drug and dietary interactions [4]. However, DOACS are more costly than warfarin, and like all anticoagulants, can increase the risk of bleeding. When selecting amongst various anticoagulant options, clinicians must weigh efficacy and safety, whether a patient can adhere to a treatment plan, and cost. In addition to clinical outcomes, patients may also prioritize convenience and ease of use.

Relatively few studies that have compared treatment satisfaction between DOACs and warfarin users in patients with VTE, particularly in non-clinical trial settings [5, 6]. This study's goal was to measure anticoagulant treatment satisfaction in a large, community-based cohort of patients anticoagulated for VTE, comparing patients taking warfarin with patients taking DOACs.

\section{Methods}

\section{Participants and setting}

The source population for the study was adults (aged $\geq 18$ years) enrolled in Kaiser Permanente Northern California (KPNC) or Kaiser Permanente Southern California (KPSC), two large, integrated healthcare delivery systems providing comprehensive care for approximately 9 million individuals across California. The source population is representative of the racially and ethnically diverse population of California [7, 8].

We identified all adults who completed an initial treatment course (e.g., 3 months) of oral anticoagulants after an incident diagnosis of acute VTE that occurred during the time period between January 1, 2010 and December 31, 2018. Incident diagnosis of VTE was defined as a clinical encounter (inpatient, emergency department, or outpatient) associated with either a primary or secondary discharge diagnosis of VTE according to the International Classification of Diseases Ninth Revision (ICD-9) or Tenth Revision (ICD-10), and with no prior VTE diagnosis or oral anticoagulant prescription in the past 4 years. The cohort was further restricted to individuals with complete information on age and gender, and with 12 months of continuous enrollment and pharmacy benefits prior to the VTE index date. VTE type was categorized as pulmonary embolism (PE) with or without other thrombosis, lower extremity deep venous thrombosis (DVT), upper extremity DVT, and other VTE (such as mesenteric thrombosis). Anticoagulant prescriptions were identified from health plan pharmacy dispensing databases. Data on subject demographics (age, self-reported gender, race, and Hispanic ethnicity) were obtained from health plan administrative databases.

We identified and invited a set of eligible patients to participate in a survey on anticoagulant treatment satisfaction. Eligibility criteria were non-deceased patients with a VTE diagnosis date between January 1, 2015 and June 30, 2018 (to capture the experience of patients once there was more widespread use of DOACs for VTE), actively enrolled in the health plan, who had a valid mailing address and/or telephone number at the time of the survey, and whose primary language was English, Spanish, or Chinese. Patients were categorized as either taking warfarin or a DOAC (dabigatran, rivaroxaban, or apixaban), using the anticoagulant prescription closest in time to the survey completion date.

Surveys were delivered by ANA Research, Inc., a market research company, and occurred in two waves, the first during Summer, 2018 and the second in Spring, 2019. Eligible 
subjects were mailed a survey invitation and, when possible, sent an email invitation as well. Follow-up phone calls were issued to non-respondents. Subjects were given the opportunity to complete the survey in English, Spanish, or Chinese. Surveys could be completed on a paper form, by telephone, or online via secure web link. An honorarium of US \$25 was offered upon survey completion. In the first survey wave, we contacted all DOAC and warfarin users with an index VTE between January, 2015 and April, 2017 to participate in web, telephone, or paper versions of the survey. In the second survey wave, patients with VTE diagnosis between May, 2017 and June, 2018 were invited to complete the web survey. To ensure adequate representation of DOAC users, we then mailed survey invitations to DOAC users who did not have a valid e-mail address or if they did not respond to the e-mail survey link.

The survey asked patients whether they took anticoagulants within the past 4 weeks and if yes, to complete the Anti-Clot Treatment Scale $\odot$ (ACTS) [9], a validated 17 item patient-reported scale that assesses treatment satisfaction with anticoagulants. Additionally, questions included whether they had ever switched from one anticoagulant to another, and had they ever experienced bleeding complications from anticoagulants. Finally, the survey asked about subjects' marital status, household income, and highest educational attainment.

\section{Statistical analysis}

The primary outcome of this analysis was anticoagulant treatment satisfaction measured by the ACTS. The ACTS is divided into two sub-scales, ACTS Burdens (assessing challenges with anticoagulation) and ACTS Benefits (assessing confidence and reassurance in anticoagulation). In addition, there are two global questions asking about overall benefit and overall burden which are not included in the scores. ACTS Burdens is reverse coded on a 5-point Likert scale and is the sum of 12 items (range 12-60). ACTS Benefits is coded from 1 to 5 and is the sum of 3 items (range 3-15). Higher scores denote greater satisfaction with treatment. We calculated the ACTS scores according to the developers' guidelines [9]. If $>50 \%$ of items were not answered by a subject, the participant's response was considered missing; otherwise individual subscale imputation to the mean was used for missing items.

We first compared the unadjusted mean treatment satisfaction (ACTS Burdens and ACTS Benefits) between patients on warfarin and DOACs. In addition to statistically significant difference, we also calculated the effect size, a measure of the size of the difference in outcomes that can inform the clinical relevance of the treatment difference [10]. Effect size was calculated as the Cohen's $d$, the difference in means divided by the pooled standard deviation. In general, an effect size of 0.20 is considered small, an effect size of 0.50 is moderate, and effect sizes of $\geq 0.80$ are large.

Next, we developed separate general multivariable linear regression models for ACTS Burdens and ACTS Benefits scores, with the primary independent variable being anticoagulant treatment category (warfarin versus DOAC), and adjusted for clinical and demographic characteristics that may be plausible confounders of the relationship between treatment type and satisfaction. The difference in mean satisfaction scores were computed as the Least Squares mean, adjusted for the means of the other covariates. For race and ethnicity, a separate category of "missing/unknown" was included. Most other variables had minimal to no missing data, so multivariable models were developed from those subjects with complete data. There was no missing data for the primary independent variable, anticoagulant treatment category. All models also included a high-dimensional propensity score (hdPS) that represented the likelihood a patient was prescribed a DOAC. In contrast to standard propensity score development, which is typically based on a set of pre-selected variables, a hdPS is developed through automated or data-driven algorithms that take advantage of the availability of large administrative data sources and may approximate point estimates of risk more accurately than standard propensity scores [11]. The hdPS for this study was developed using 5 dimensions (principal inpatient/emergency department [ED] diagnoses only, secondary inpatient/ ED diagnoses, outpatient/ED diagnoses, procedures from any setting, and outpatient drug claims) and used a lookback period of 4 years. Within each dimension, the 300 most common codes were ranked by frequency, and then the final hdPS was developed by regressing the exposure variable (anticoagulation treatment type) on the covariates. The hdPS was then included as an adjustment variable in the multivariable models.

Finally, because patients who change anticoagulant treatment types may have done so due to dissatisfaction with a given treatment, we repeated the analyses restricting to patients who did not report a history of switching anticoagulants.

This study was approved by the Kaiser Permanente Northern California Institutional Review Board. The authors had full access to all the data in the study and take responsibility for its integrity and the data analysis.

\section{Results}

Out of 12,737 eligible patients approached to participate in the original survey, 4771 completed at least $80 \%$ of the items and 2244 people answered at least 1 item on the ACTS instrument (not all subjects who answered the survey reported actively taking anticoagulants and so were not 
eligible for the treatment satisfaction portion of the survey). Twenty-seven people answered $<50 \%$ of the ACTS items and were excluded from the analysis, resulting in a final analytic population of 2217 patients, of whom 969 were taking a DOAC and 1248 were taking warfarin. Similar proportions of warfarin and DOAC users completed the ACTS instrument, with $98.2 \%$ of warfarin users answering $\geq 90 \%$ of the ACTS items and $98.8 \%$ of DOAC users $(\mathrm{p}=0.26)$.

Compared with warfarin users, patients taking DOACs were on average younger and with higher educational attainment and household income (Table 1). Patients taking DOACs were more likely to have been diagnosed with their index VTE in recent years, reflecting increased uptake of DOACs over time (Table 1). A larger proportion of DOAC users reported a history of switching from another anticoagulant $(42.9 \%)$ compared with only $9.5 \%$ of warfarin users $(\mathrm{p}<0.0001)$. Patients who reported switching from warfarin to a DOAC were more likely to cite convenience $(40.6 \% \mathrm{v}$. $19.3 \%, \mathrm{p}<0.0001)$ and drug-drug interactions $(13 \%$ v. $5 \%$, $\mathrm{p}=0.016)$ as reasons for switching anticoagulants.

On unadjusted analysis, DOAC users were on average more satisfied than warfarin users with anticoagulant treatment, with both higher mean ACTS Burdens score (52.9 vs. $50.6, \mathrm{p}<0.0001)$ and higher ACTS Benefits score (10.4 vs. $10.1, p=0.005$, Table 2). The clinical effect size of these differences was small overall (0.29 for ACTS Burdens and 0.12 for ACTS Benefits).

After multivariable adjustment, the difference in satisfaction between DOAC and warfarin users persisted, with DOAC users having higher mean ACTS Burdens (50.18 v. 48.01, $\mathrm{p}<0.0001$, Table 3 ) and ACTS Benefits scores (10.21 v. 9.84, $p=0.046$, Table 4). The final models of treatment satisfaction were adjusted for age, gender, race, Hispanic ethnicity, household income, educational attainment, marital status, patient-reported history of bleeding, VTE type, year of diagnosis, whether the patient reported switching anticoagulants, and the hdPS. Several other factors were also associated with differences in treatment satisfaction. In particular, women, younger age, and a history of bleeding were associated with more perceived anticoagulant burden (Table 3), while a history of switching anticoagulants and prior bleeding were associated with lower perceived benefits (Table 4).

In the subgroup analysis of patients who did not report a history of switching anticoagulants, patients taking DOACs continued to have a higher mean ACTS Burdens Score (50.84 v. $48.37, \mathrm{p}=0.0016)$, but the difference in mean ACTS Benefits Score did not remain statistically different (Online Appendix Tables A and B).

\section{Discussion}

In this study of 2217 people taking anticoagulants for VTE, patients taking DOACs reported greater anticoagulant treatment satisfaction than did warfarin users, although the magnitude of the difference was small. Few studies have directly compared treatment satisfaction between DOACs and warfarin for VTE in non-trial settings. The initial development and validation of the ACTS Score were based on the EINSTEIN DVT and EINSTEIN PE randomized trials and measured treatment satisfaction only up to 12 months after drug initiation $[12,13]$. The EINSTEIN studies found that rivaroxaban was associated with greater treatment satisfaction than enoxaparin/vitamin $\mathrm{K}$ antagonists for the initial treatment of thromboembolism. Subsequently, a sub-analysis of the observational XArelto for Long-term and Initial Anticoagulation in venous thromboembolism (XALIA) study compared treatment satisfaction between rivaroxaban or enoxaparin/vitamin K antagonists for DVT [5]. After a median $\sim 180$ days of treatment, rivaroxaban was associated with less burden. In these studies of rivaroxaban, the mean ACTS Burdens score ranged from 55.2 to 56.1 and the mean ACTS Benefits score ranged from 11.7 to 12.1. Interestingly, these scores are higher than the mean scores found in our study population. Our study was conducted in a diverse population, based in the United States (as opposed to a primarily European population) and included patients who were beyond the initial treatment phase of anticoagulation. Patients enrolled in clinical trial settings may also be more highly selected and closely followed than patients in unselected real-world settings, highlighting the importance of conducting evaluations of actual clinical practice.

The primary objective of this study was to compare treatment satisfaction between DOAC and warfarin users. We did, in addition, find differences in treatment satisfaction among several patient sub-groups. Specifically, women and people of younger ages perceived more burden associated with anticoagulant treatment, regardless of type of therapy. A history of needing to seek medical attention for anticoagulant-related bleeding was associated with more perceived burden and lower benefits.

Our study had several limitations. As an observational study of clinical care, patients were not randomly assigned to take warfarin or DOACs. Although we applied high dimensional propensity score approaches to better balance the two groups, it is possible that treatment satisfaction may have been influenced by factors leading to preferential use of one anticoagulant over another, such framing of medications by individual clinicians, intercurrent health events, and impact 
Table 1 Survey of 2217 patients taking anticoagulants for venous thromboembolism, comparing characteristics of DOAC and warfarin users

\begin{tabular}{|c|c|c|c|}
\hline Characteristic & $\begin{array}{l}\text { DOAC users } \\
(\mathrm{n}=969)\end{array}$ & $\begin{array}{l}\text { Warfarin users } \\
(\mathrm{n}=1248)\end{array}$ & p-value \\
\hline Age at time of survey & & & 0.016 \\
\hline$\leq 54$ years & $158(16.3 \%)$ & $226(18.1 \%)$ & \\
\hline $55-64$ years & $210(21.7 \%)$ & $254(20.4 \%)$ & \\
\hline $65-74$ years & $317(32.7 \%)$ & $352(28.2 \%)$ & \\
\hline $75-84$ years & $220(22.7 \%)$ & $293(23.5 \%)$ & \\
\hline$\geq 85$ years & $64(6.6 \%)$ & $123(9.9 \%)$ & \\
\hline Women & $404(41.7 \%)$ & $551(44.2 \%)$ & 0.25 \\
\hline Race & & & 0.17 \\
\hline White & $738(76.2 \%)$ & $895(71.7 \%)$ & \\
\hline Black & $88(9.1 \%)$ & $131(10.5 \%)$ & \\
\hline Asian or Pacific Islander & $25(2.6 \%)$ & $32(2.6 \%)$ & \\
\hline Multiple or other & $87(9 \%)$ & $136(10.9 \%)$ & \\
\hline Missing & $31(3.2 \%)$ & $54(4.3 \%)$ & \\
\hline Ethnicity & & & 0.41 \\
\hline Hispanic & $94(9.7 \%)$ & $140(11.2 \%)$ & \\
\hline Non-Hispanic & $849(87.6 \%)$ & $1069(85.7 \%)$ & \\
\hline Missing & $26(2.7 \%)$ & $39(3.1 \%)$ & \\
\hline Preferred language & & & 0.60 \\
\hline English & $921(95 \%)$ & $1168(93.6 \%)$ & \\
\hline Spanish & $17(1.8 \%)$ & $31(2.5 \%)$ & \\
\hline Other, specify & $3(0.3 \%)$ & $7(0.6 \%)$ & \\
\hline Missing & $23(2.4 \%)$ & $36(2.9 \%)$ & \\
\hline Multiple mark & $5(0.5 \%)$ & $6(0.5 \%)$ & \\
\hline Highest level of education & & & $<0.0001$ \\
\hline Less than HS Graduate & $33(3.4 \%)$ & $42(3.4 \%)$ & \\
\hline 12th grade, HS graduate or GED & $101(10.4 \%)$ & $199(15.9 \%)$ & \\
\hline Some college or technical school & $356(36.7 \%)$ & $511(40.9 \%)$ & \\
\hline Completed Bachelor degree & $230(23.7 \%)$ & $250(20 \%)$ & \\
\hline Completed Graduate degree & $212(21.9 \%)$ & $197(15.8 \%)$ & \\
\hline Unknown/missing & $37(3.8 \%)$ & $49(3.9 \%)$ & \\
\hline Total household income & & & 0.007 \\
\hline Under $\$ 15,000$ & $39(4 \%)$ & $47(3.8 \%)$ & \\
\hline$\$ 15,000$ to $\$ 25,000$ & $52(5.4 \%)$ & $93(7.5 \%)$ & \\
\hline$\$ 25,001$ to $\$ 35,000$ & $56(5.8 \%)$ & $89(7.1 \%)$ & \\
\hline$\$ 35,001$ to $\$ 50,000$ & $69(7.1 \%)$ & $130(10.4 \%)$ & \\
\hline$\$ 50,001$ to $\$ 65,000$ & $82(8.5 \%)$ & $118(9.5 \%)$ & \\
\hline$\$ 65,001$ to $\$ 80,000$ & $94(9.7 \%)$ & $112(9 \%)$ & \\
\hline$\$ 80,001$ to $\$ 100,000$ & $93(9.6 \%)$ & $132(10.6 \%)$ & \\
\hline$\$ 100,001$ to $\$ 150,000$ & $150(15.5 \%)$ & $150(12 \%)$ & \\
\hline More than $\$ 150,000$ & $123(12.7 \%)$ & $121(9.7 \%)$ & \\
\hline I do not want to answer this question & $162(16.7 \%)$ & $185(14.8 \%)$ & \\
\hline Missing & $49(5.1 \%)$ & $71(5.7 \%)$ & \\
\hline Marital status & & & 0.50 \\
\hline Married & $599(61.8 \%)$ & $731(58.6 \%)$ & \\
\hline Not married but in a committed relationship & $38(3.9 \%)$ & $63(5 \%)$ & \\
\hline Widowed & $97(10 \%)$ & $128(10.3 \%)$ & \\
\hline Single, divorced, or separated & $201(20.7 \%)$ & $282(22.6 \%)$ & \\
\hline Missing & $34(3.5 \%)$ & $44(3.5 \%)$ & \\
\hline Family history of DVT/PE & $203(20.9 \%)$ & $239(19.2 \%)$ & 0.28 \\
\hline
\end{tabular}


Table 1 (continued)

\begin{tabular}{|c|c|c|c|}
\hline Characteristic & $\begin{array}{l}\text { DOAC users } \\
(\mathrm{n}=969)\end{array}$ & $\begin{array}{l}\text { Warfarin users } \\
(\mathrm{n}=1248)\end{array}$ & p-value \\
\hline Year of index VTE & & & $<0.0001$ \\
\hline 2015 & $156(16.1 \%)$ & $462(37 \%)$ & \\
\hline 2016 & $316(32.6 \%)$ & $483(38.7 \%)$ & \\
\hline 2017 & $322(33.2 \%)$ & $231(18.5 \%)$ & \\
\hline 2018 & $175(18.1 \%)$ & $72(5.8 \%)$ & \\
\hline Switched from one anticoagulant to another & & & $<0.0001$ \\
\hline No & $515(53.1 \%)$ & $1074(86.1 \%)$ & \\
\hline Yes & $416(42.9 \%)$ & $119(9.5 \%)$ & \\
\hline Missing & $10(1 \%)$ & $21(1.7 \%)$ & \\
\hline Do not know & $28(2.9 \%)$ & $34(2.7 \%)$ & \\
\hline \multicolumn{4}{|c|}{ If switched anticoagulants, reasons for changing (can list more than one) } \\
\hline Side effects & $92(22.1 \%)$ & $29(24.4 \%)$ & 0.60 \\
\hline Convenience & $169(40.6 \%)$ & $23(19.3 \%)$ & $<0.0001$ \\
\hline Diet or drug interactions & $54(13 \%)$ & $6(5 \%)$ & 0.02 \\
\hline Cost & $37(8.9 \%)$ & $10(8.4 \%)$ & 0.87 \\
\hline Difficulty with blood thinner control & $76(18.3 \%)$ & $26(21.8 \%)$ & 0.38 \\
\hline I do not know & $93(22.4 \%)$ & $36(30.3 \%)$ & 0.08 \\
\hline $\begin{array}{l}\text { Sought medical assistance for bleeding problems } \\
\text { while on anticoagulants }\end{array}$ & & & 0.057 \\
\hline No & $862(89 \%)$ & $1065(85.3 \%)$ & \\
\hline Yes & $99(10.2 \%)$ & $162(13 \%)$ & \\
\hline Missing & $4(0.4 \%)$ & $12(1 \%)$ & \\
\hline Do not know & $4(0.4 \%)$ & $9(0.7 \%)$ & \\
\hline
\end{tabular}

Table 2 Anticoagulant treatment satisfaction of 2217 patients taking anticoagulants for venous thromboembolism, measured by the ACTS Burdens, ACTS Benefits, and ACTS Global Satisfaction scores

\begin{tabular}{lcrrr}
\hline & $\begin{array}{l}\text { DOAC users } \\
(\mathrm{n}=969)\end{array}$ & $\begin{array}{l}\text { Warfarin users } \\
(\mathrm{n}=1248)\end{array}$ & Effect size $^{\mathrm{a}}$ & p-value \\
\hline ACTS Burden Scale (mean, SD) & $52.9(7.20)$ & $50.6(8.50)$ & 0.29 & 0.15 \\
ACTS Burden Global (mean, SD) & $4.2(0.99)$ & $4.0(1.04)$ & 0.0001 \\
ACTS Benefit Scale (mean, SD) & $10.4(2.98)$ & $10.1(3.06)$ & 0.12 & 0.0001 \\
ACTS Benefit Global (mean, SD) & $3.2(1.24)$ & $3.1(1.24)$ & 0.08 \\
\hline
\end{tabular}

Higher scores indicate greater treatment satisfaction

$S D$ standard deviation

${ }^{a}$ An effect size of 0.20 is considered small, an effect size of 0.50 is moderate, and effect sizes of $\geq 0.80$ are large

on lifestyle. Although our survey was large, with over 2000 responses, some people who were eligible to participate either declined or did not respond and it is possible that the experiences of people who answered the survey do not fully represent the perspectives of the overall population.

In summary, this large survey of community-based patients taking anticoagulants for VTE found greater treatment satisfaction among patients taking DOACs, although the differences were small clinically. Our study was not designed to determine whether there is an association between treatment satisfaction and adherence to anticoagulant treatment. However, other studies have found that increased satisfaction has positive impact on medication compliance and persistence [14]. Findings from this study 
Table 3 Anticoagulant treatment burden among patients with venous thromboembolism: adjusted least mean ACTS Burdens score with 95\% confidence intervals (CI), and P-values for the difference in means from multivariable general linear model*

\begin{tabular}{|c|c|c|c|c|}
\hline Variable & $\begin{array}{l}\text { Adjusted mean ACTS } \\
\text { Burdens score }\end{array}$ & $95 \%$ CI (low) & 95\% CI (high) & p-value \\
\hline \multicolumn{5}{|l|}{ Treatment type } \\
\hline Warfarin & 48.01 & 46.80 & 49.23 & Ref \\
\hline DOAC & 50.18 & 48.99 & 51.37 & $<0.0001$ \\
\hline \multicolumn{5}{|l|}{ Age at time of survey } \\
\hline$\leq 54$ & 45.28 & 44.01 & 46.55 & Ref \\
\hline $55-64$ & 48.25 & 46.98 & 49.52 & $<0.0001$ \\
\hline $65-74$ & 49.73 & 48.48 & 50.97 & $<0.0001$ \\
\hline $75-84$ & 50.56 & 49.28 & 51.85 & $<0.0001$ \\
\hline$\geq 85$ & 51.67 & 50.07 & 53.27 & $<0.0001$ \\
\hline \multicolumn{5}{|l|}{ Gender } \\
\hline Male & 49.60 & 48.42 & 50.78 & Ref \\
\hline Female & 48.60 & 47.44 & 49.75 & 0.0049 \\
\hline \multicolumn{5}{|l|}{ Race } \\
\hline White & 49.77 & 48.70 & 50.83 & Ref \\
\hline Asian or Pacific Islander & 49.42 & 47.17 & 51.66 & 0.74 \\
\hline Black & 49.34 & 47.87 & 50.81 & 0.47 \\
\hline Other/missing & 47.87 & 46.58 & 49.15 & 0.0015 \\
\hline \multicolumn{5}{|l|}{ Ethnicity } \\
\hline Not Hispanic or missing ethnicity & 49.66 & 48.58 & 50.74 & Ref \\
\hline Hispanic & 48.54 & 47.07 & 50.00 & 0.0901 \\
\hline \multicolumn{5}{|l|}{ Highest level of education } \\
\hline Less than HS Graduate & 48.16 & 46.04 & 50.28 & Ref \\
\hline 12th grade, HS graduate or GED, some college or technical school & 49.62 & 48.50 & 50.74 & 0.16 \\
\hline Completed Bachelor degree & 49.79 & 48.54 & 51.04 & 0.13 \\
\hline Completed Graduate degree & 48.83 & 47.53 & 50.12 & 0.55 \\
\hline \multicolumn{5}{|l|}{ Income } \\
\hline$\leq \$ 25,000$ & 48.39 & 46.97 & 49.81 & Ref \\
\hline$\$ 25,001$ to $\$ 50,000$ & 49.62 & 48.30 & 50.94 & 0.068 \\
\hline$\$ 50,001$ to $\$ 100,000$ & 49.73 & 48.50 & 50.96 & 0.0355 \\
\hline$\geq \$ 100,001$ & 49.44 & 48.09 & 50.78 & 0.1345 \\
\hline Prefer not to answer & 48.31 & 46.93 & 49.70 & 0.909 \\
\hline \multicolumn{5}{|l|}{ Marital status } \\
\hline Single, divorced, widowed or separated & 49.22 & 48.09 & 50.35 & Ref \\
\hline Married, or not married but in a committed relationship & 48.98 & 47.75 & 50.21 & 0.56 \\
\hline \multicolumn{5}{|l|}{ VTE type } \\
\hline Pulmonary embolism & 48.31 & 47.28 & 49.34 & \\
\hline Lower extremity deep vein thrombosis & 48.82 & 47.76 & 49.88 & 0.15 \\
\hline Upper extremity deep vein thrombosis & 48.46 & 46.56 & 50.36 & 0.86 \\
\hline Other VTE (mesenteric venous thrombosis, other VTE, unknown VTE) & 50.80 & 48.76 & 52.84 & 0.0096 \\
\hline \multicolumn{5}{|l|}{ Year of index VTE } \\
\hline 2015 & 49.58 & 48.34 & 50.82 & Ref \\
\hline 2016 & 49.18 & 47.99 & 50.37 & 0.36 \\
\hline 2017 & 48.50 & 47.25 & 49.75 & 0.03 \\
\hline 2018 & 49.13 & 47.67 & 50.60 & 0.49 \\
\hline \multicolumn{5}{|l|}{ History of switching anticoagulants } \\
\hline No & 49.45 & 48.32 & 50.59 & Ref \\
\hline Yes & 48.74 & 47.50 & 49.99 & 0.096 \\
\hline \multicolumn{5}{|l|}{ History of bleeding issue } \\
\hline No & 51.21 & 50.14 & 52.27 & Ref \\
\hline Yes & 46.99 & 45.62 & 48.37 & $<0.0001$ \\
\hline
\end{tabular}

Higher scores denote greater treatment satisfaction

*Model developed from 2211 survey respondents without missing data and included all listed covariates in addition to a high-dimensional propensity score (hdPS). The c-statistic for the hdPS was 0.858 
Table 4 Anticoagulant treatment benefits among patients with venous thromboembolism: adjusted least mean ACTS Benefits score with 95\% confidence intervals (CI), and P-values for the difference in means from multivariable general linear model*

\begin{tabular}{|c|c|c|c|c|}
\hline Variable & $\begin{array}{l}\text { Adjusted mean ACTS } \\
\text { Benefits score }\end{array}$ & 95\% CI (low) & 95\% CI (high) & $\mathrm{p}$-value \\
\hline \multicolumn{5}{|l|}{ Treatment type } \\
\hline Warfarin & 9.84 & 9.34 & 10.33 & Ref \\
\hline DOAC & 10.21 & 9.73 & 10.69 & 0.046 \\
\hline \multicolumn{5}{|l|}{ Age at time of survey } \\
\hline$\leq 54$ & 9.91 & 9.40 & 10.43 & Ref \\
\hline $55-64$ & 10.03 & 9.52 & 10.54 & 0.60 \\
\hline $65-74$ & 10.26 & 9.75 & 10.76 & 0.10 \\
\hline $75-84$ & 9.86 & 9.34 & 10.38 & 0.81 \\
\hline$\geq 85$ & 10.06 & 9.41 & 10.71 & 0.63 \\
\hline \multicolumn{5}{|l|}{ Gender } \\
\hline Male & 10.12 & 9.64 & 10.60 & Ref \\
\hline Female & 10.07 & 9.61 & 10.52 & 0.16 \\
\hline \multicolumn{5}{|l|}{ Race } \\
\hline White & 10.05 & 9.61 & 10.48 & Ref \\
\hline Asian or Pacific Islander & 10.38 & 9.47 & 11.29 & 0.44 \\
\hline Black & 9.67 & 9.08 & 10.27 & 0.12 \\
\hline Other or missing race & 10.00 & 9.47 & 10.52 & 0.83 \\
\hline \multicolumn{5}{|l|}{ Ethnicity } \\
\hline Not Hispanic or missing ethnicity & 9.89 & 9.45 & 10.33 & Ref \\
\hline Hispanic & 10.16 & 9.56 & 10.76 & 0.31 \\
\hline \multicolumn{5}{|l|}{ Highest level of education } \\
\hline Less than HS Graduate & 9.48 & 8.62 & 10.34 & Ref \\
\hline 12th grade, HS graduate or GED, some college or technical school & 10.07 & 9.61 & 10.52 & 0.16 \\
\hline Completed Bachelor degree & 10.33 & 9.83 & 10.84 & 0.054 \\
\hline Completed Graduate degree & 10.21 & 9.69 & 10.73 & 0.10 \\
\hline \multicolumn{5}{|l|}{ Income } \\
\hline$\leq \$ 25,000$ & 9.71 & 9.13 & 10.28 & Ref \\
\hline$\$ 25,001$ to $\$ 50,000$ & 10.09 & 9.56 & 10.63 & 0.16 \\
\hline$\$ 50,001$ to $\$ 100,000$ & 10.20 & 9.70 & 10.70 & 0.058 \\
\hline$\geq \$ 100,001$ & 10.22 & 9.67 & 10.76 & 0.070 \\
\hline Prefer not to answer & 9.90 & 9.34 & 10.46 & 0.51 \\
\hline \multicolumn{5}{|l|}{ Marital status } \\
\hline Single, divorced, widowed or separated & 9.89 & 9.43 & 10.35 & \\
\hline Married, or not married but in a committed relationship & 10.15 & 9.65 & 10.65 & 0.11 \\
\hline \multicolumn{5}{|l|}{ VTE type } \\
\hline Pulmonary embolism & 9.96 & 9.55 & 10.38 & Ref \\
\hline Lower extremity deep vein thrombosis & 9.77 & 9.34 & 10.20 & 0.17 \\
\hline Other VTE (mesenteric venous thrombosis, other VTE, unknown VTE) & 10.03 & 9.25 & 10.80 & 0.86 \\
\hline Upper extremity deep vein thrombosis & 10.33 & 9.51 & 11.16 & 0.34 \\
\hline \multicolumn{5}{|l|}{ Year of index VTE } \\
\hline 2015 & 10.32 & 9.82 & 10.83 & Ref \\
\hline 2016 & 9.91 & 9.43 & 10.40 & 0.019 \\
\hline 2017 & 10.04 & 9.53 & 10.55 & 0.16 \\
\hline 2018 & 9.81 & 9.22 & 10.41 & 0.051 \\
\hline \multicolumn{5}{|l|}{ History of switching anticoagulant } \\
\hline No & 10.20 & 9.74 & 10.66 & Ref \\
\hline Yes & 9.85 & 9.34 & 10.35 & 0.043 \\
\hline \multicolumn{5}{|l|}{ History of bleeding issue } \\
\hline No & 10.39 & 9.96 & 10.82 & Ref \\
\hline Yes & 9.66 & 9.10 & 10.21 & 0.0006 \\
\hline
\end{tabular}

*Developed on 2207 survey respondents without missing data and included all listed covariates in addition to a high-dimensional propensity score (hdPS). The c-statistic for the hdPS was 0.861

Higher scores denote greater treatment satisfaction 
can help clinicians inform patients of the comparative differences between these two anticoagulant options. If all other factors are equal, such as medical appropriateness and cost, then patients may prefer being on a DOAC.

Supplementary Information The online version contains supplementary material available at https://doi.org/10.1007/s11239-021-02437-z.

Funding Research reported in this article was funded through a PatientCentered Outcomes Research Institute (PCORI) Award (NOACs1510-32651) and the National Heart, Lung, and Blood Institute of the National Institutes of Health (K24HL141354). The content is solely the responsibility of the authors and does not necessarily represent the official views of PCORI or the National Institutes of Health.

Data availability Upon request.

Code availability Upon request.

\section{Declarations}

Conflict of interest Margaret Fang: Research funding: NHLBI, NIA, PCORI. Priya Prasad: None. Alan Go: Research funding: NHLBI, NIDDK, NIA, PCORI, Bristol Meyers Squibb, Pfizer. Sue Hee Sung: None. Dongjie Fan: None. Kristi Reynolds: Research funding: PCORI. Cecilia Portugal: None. Jin-Wen Hsu: None.

Ethical approval This study was approved by the Kaiser Permanente Northern California Institutional Review Board and consent was obtained from all study participants.

Open Access This article is licensed under a Creative Commons Attribution 4.0 International License, which permits use, sharing, adaptation, distribution and reproduction in any medium or format, as long as you give appropriate credit to the original author(s) and the source, provide a link to the Creative Commons licence, and indicate if changes were made. The images or other third party material in this article are included in the article's Creative Commons licence, unless indicated otherwise in a credit line to the material. If material is not included in the article's Creative Commons licence and your intended use is not permitted by statutory regulation or exceeds the permitted use, you will need to obtain permission directly from the copyright holder. To view a copy of this licence, visit http://creativecommons.org/licenses/by/4.0/.

\section{References}

1. Heit JA, Crusan DJ, Ashrani AA, Petterson TM, Bailey KR (2017) Effect of a near-universal hospitalization-based prophylaxis regimen on annual number of venous thromboembolism events in the US. Blood 130:109-114

2. Fang MC, Fan D, Sung SH, Witt DM, Schmelzer JR, Williams MS, Yale SH, Baumgartner C, Go AS (2019) Treatment and outcomes of acute pulmonary embolism and deep venous thrombosis: the CVRN VTE study. Am J Med 132:1450-1457 e1
3. Ortel TL, Neumann I, Ageno W, Beyth R, Clark NP, Cuker A, Hutten BA, Jaff MR, Manja V, Schulman S, Thurston C, Vedantham S, Verhamme P, Witt DM, D Florez I, Izcovich A, Nieuwlaat R, Ross S, J Schünemann H, Wiercioch W, Zhang Y, Zhang Y (2020) American Society of Hematology 2020 guidelines for management of venous thromboembolism: treatment of deep vein thrombosis and pulmonary embolism. Blood Adv 4:4693-4738

4. Witt DM, Nieuwlaat R, Clark NP, Ansell J, Holbrook A, Skov J, Shehab N, Mock J, Myers T, Dentali F, Crowther MA, Agarwal A, Bhatt M, Khatib R, Riva JJ, Zhang Y, Guyatt G (2018) American Society of Hematology 2018 guidelines for management of venous thromboembolism: optimal management of anticoagulation therapy. Blood Adv 2:3257-3291

5. Cano S, Mantovani L, Folkerts K, Gebel M, Sahin K, Zell E, Monje D, Schneider J, Eickels MV, Haas S, Kreutz R, Ageno W, Turpie AGG (2018) Patient-reported treatment experience with oral rivaroxaban: results from the noninterventional XALIA study of deep-vein thrombosis. TH Open 2:e139-e146

6. Keita I, Aubin-Auger I, Lalanne C, Aubert JP, Chassany O, Duracinsky M, Mahe I (2017) Assessment of quality of life, satisfaction with anticoagulation therapy, and adherence to treatment in patients receiving long-course vitamin $\mathrm{K}$ antagonists or direct oral anticoagulants for venous thromboembolism. Patient Prefer Adherence 11:1625-1634

7. Gordon N, Lin T (2016) The Kaiser Permanente Northern California adult member health survey. Perm J. 20(4):15-225. https:// doi.org/10.7812/TPP/15-225

8. Koebnick C, Langer-Gould AM, Gould MK, Chao CR, Iyer RL, Smith N, Chen W, Jacobsen SJ (2012) Sociodemographic characteristics of members of a large, integrated health care system: comparison with US Census Bureau data. Perm J 16:37-41

9. Cano SJ, Lamping DL, Bamber L, Smith S (2012) The Anti-Clot Treatment Scale (ACTS) in clinical trials: cross-cultural validation in venous thromboembolism patients. Health Qual Life Outcomes 10:120

10. Fritz CO, Morris PE, Richler JJ (2012) Effect size estimates: current use, calculations, and interpretation. J Exp Psychol Gen 141:2-18

11. Neugebauer R, Schmittdiel JA, Zhu Z, Rassen JA, Seeger JD, Schneeweiss $S$ (2015) High-dimensional propensity score algorithm in comparative effectiveness research with time-varying interventions. Stat Med 34:753-781

12. Bamber L, Wang MY, Prins MH, Ciniglio C, Bauersachs R, Lensing AW, Cano SJ (2013) Patient-reported treatment satisfaction with oral rivaroxaban versus standard therapy in the treatment of acute symptomatic deep-vein thrombosis. Thromb Haemost 110:732-741

13. Prins MH, Bamber L, Cano SJ, Wang MY, Erkens P, Bauersachs R, Lensing AW (2015) Patient-reported treatment satisfaction with oral rivaroxaban versus standard therapy in the treatment of pulmonary embolism; results from the EINSTEIN PE trial. Thromb Res 135:281-288

14. Barbosa CD, Balp MM, Kulich K, Germain N, Rofail D (2012) A literature review to explore the link between treatment satisfaction and adherence, compliance, and persistence. Patient Prefer Adherence 6:39-48

Publisher's Note Springer Nature remains neutral with regard to jurisdictional claims in published maps and institutional affiliations. 